\title{
On Auxiliary Function of Sports Journals on Physical Education Teaching
}

\author{
Chen Yurong \\ (Hainan Medical College, Haikou, Hainan 571199)
}

Keywords: Sports journals; Physical education teaching; Auxiliary

\begin{abstract}
Modern society means not only an intelligence competition, but also a physical struggle. Students have to develop morally, intellectually and physically. Relying only on physical education teaching books is not enough for the cultivation of comprehensive talents. In sports teaching, the use of sports journals as an auxiliary tool is a very effective method.
\end{abstract}

\section{Introduction}

In recent years, with the rapid development of national economy and ascension of people's economic life level, our country sports enterprise develops subsequently. Especially since the reform and opening, domestic colleges and universities are booming. Almost every school sets sports profession, even sports institute according to their own characteristics. This further promotes the output of sports talents. These sports talents mastering professional knowledge and skills get into primary school, middle school and high school, which further promotes school sports teaching level ascension and school sports talent structure optimization. Now it is generally believed that: the purpose of physical education teaching is to promote the development of students' physical and mental health, cultivate students' sports ability, and make them aware of the importance of physical training in the whole life. To realize this purpose, just rely on traditional sports teaching is obviously not enough. This is because sports teaching pattern is in the update, not just in sports teaching professional knowledge, but students demand for knowledge is more and more diversified. Therefore, we must seek other auxiliary means to better promote the development of sports teaching. Sports journals are an important auxiliary tool. Sports journals-assisted instruction is under the guidance of teachers, and students make use of school library and database resources. On the basis of careful reading and understanding of journal articles, students share and discuss with teacher and classmates to supplement the shortage of the existing sports books [1-2].

\section{Advantages of sports journals over traditional teaching materials}

A. Sports periodical resources are rich with fast update speed

In general, the updating cycle of teaching material is much longer than journals, which means that a lot of new theories and techniques can't appear in textbooks. And many textbooks have their own focus, and the emphasis clearly cannot meet the needs of all students' interest. Moreover, journals, especially the emergence of network journals, greatly improve the speed of access to information. This is what traditional teaching materials and books cannot do. With the development of information technology and transportation technology, there is great progress in all journals, including sports journals. Network information resources are exponentially growing, but these resources are not messy and not easy to query. They all have corresponding sports publications, and the publisher will upload their own sports periodical resources to corresponding database to facilitate people to search and download. Also, the publishing of periodicals will interpret and analyze the latest sports theory knowledge, new technology and new formats, and update quickly. This greatly helps sports teachers for referring to journals, and tracking new sports dynamics. Books and methods of traditional physical education teaching mode tend to be older, and teaching mode is single, which often fail to keep pace with the Times and technical trend, and cannot satisfy the need of modern physical education teaching. 
B. Improve the traditional teaching mode and stimulate interest in learning

As is known to all, sports teaching is different from other places because it is practical. Many students also think that classroom teaching is of little importance for physical education teaching, and classroom teaching mode is single. Mainly, the teacher speaks on the podium, and students listen below. Sometimes the teacher gives some heuristic teaching, but more factual teaching, which cannot inspire students' interest. Students agree that textbook knowledge can be basically gained through students' self-study without teacher's explanation. This obviously can't adapt to the demand for sports talents training now. And sports journals can effectively solve these problems. This is because students consult and organize sports journals through their own interests, which can motivate their autonomous learning ability.

\section{Auxiliary function of sports journals on physical education teaching}

A. Fast passage between campus and social communication.

Campus culture is unique temperament and soul of a school. Each campus mostly has its own unique sports culture and advantageous sports. The emergence of sports journals makes connection between campus and society more convenient and clear. Teachers and students can contact and understand sports dynamic through a variety of sports journals at home and abroad, understand the latest sports news at home and abroad, sports new technology, some new trend of sports development and new direction of sports theory research. These undoubtedly enriched teacher and student's after school life, and make the way they get information more convenient and faster.

B. Teachers and students have free access to information to broaden their horizons.

Sports journals contain vast amounts of information every day, and there has been a constant update and enriches of information, teacher and students can get all kinds of information very conveniently and fast, and at the time of access to information, they are often not restricted by time and space. It's very convenient to enrich their knowledge level and horizon, which will not only help them understand, digest and enrich their professional knowledge, but can also aim at the international front, follow age and international frontier.

C. Broaden teachers' theoretical knowledge and improve teachers' professional level

Era is in the development, so as social progress and sports, too. Many people think sports don't need theory knowledge, and a large number of practices are enough. In fact, this is very wrong. It is like our country's national sport "table tennis". After entering the Olympic Games, table tennis format has changed a lot; table tennis technology has also great progress. Of course, every progress represents a table tennis technical improvement. Ascension of each technology has its deep theoretical foundation and abundant practical basis, which is the result of athletes and coaches trial, error and summary. The theoretical basis is the essential condition of technological innovation. One aspect of modern teacher's professional standards is to require teachers to have profound professional theory knowledge, international academic field vision, and have modern education technology. Physical education teachers' teaching means and methods can only be improved and upgraded by fully understanding and mastering the theoretical knowledge and education technology. And the theory knowledge and education technology are generally appear in the latest sports journals. Therefore, sports journals class periodical is a very important learning position in addition to sports teaching material for sports teachers. Teacher of physical education must have literature for sports institute. In addition to physical education teaching, sports study is a very important content for sports teachers. From the start of the project, project design, project implementation details and final project summary, it is inseparable from sports journals. For students, only on the basis of fully understanding of theoretical knowledge can they better grasp the technology, and even make technical breakthrough [3].

D. Cultivate students' interest and improve students' sports skills

Along with the continuous improvement of teaching mode, traditional sports teaching model cannot keep pace with modern sports teaching mode. Traditional irrigation duck type teaching mode cannot effectively develop students' interest in sports activities, so it is not good for sports teaching to the students. In open teaching environment, students can seek more knowledge of mining 
according to their own interests. In the process of reading, gradually train students' better understanding for the beloved sports. This will further deepen students' master of sports skills theoretical knowledge. Under rich theoretical support, students can improve their athletic skills according to their practical activities. In this process, students' information collection and information processing ability will be improved. Then, after some discussion in the classroom, students' ability for problem analysis and solving will be enhanced. Students retrieve result and classroom discussion result according to their own literature study, and hand in the teacher in written form. In the process, students' writing ability and logical thinking ability ascend. Sports journals in sports teaching, therefore, are of great help, which not only can help students to cultivate their interest in physical education, but cultivate sports skills and students' comprehensive ability [4-5].

\section{Suggestions of using sports journals in assisting teaching}

A. Give full play to students' initiative with reasonable guide.

On the retrieval of periodicals, reading and organizing, students' initiative plays a role. But in the process, students' retrieve journals may not necessarily comprehensive. In the process of reading understanding, there may be some deviation or some they don't even know, PE teachers may give guidance and correction. Especially for some sports professional students, their own scientific and cultural level and learning ability are poor. If with no guidance and help, they find it difficult to finish the task.

B. Select appropriate sports journals with reasonable arrangement of progress.

When arranging students' sports journals lanyard in sports teaching, especially in assigned students' discussion topics, the teacher should keep in mind the students' existing sports knowledge level and students' ability to sports knowledge learning. The teacher can recommend some journals according to their own past experience and let the students screen according to their own subject. This can help to improve students' retrieval efficiency and self-confidence. Now there are many types of sports journals, and the content generally stays in theory research. These tend to be professional and academic, and students are relatively difficult to understand the connotation. For different age groups and different sports interests of students, the teacher should recommend journals reasonably according to their specific conditions in their levels of knowledge and interest.

C. Associate theory with practice, and pay attention to sports innovative talent training

General sports journal, especially some sports academic periodicals, are more on the interpretation of teaching theory knowledge, and explore more new technology and new methods. But physical education puts more emphasis on practical teaching and only on the basis of a lot of practice; students can have a better understanding of knowledge in sports. As other teaching, in sports teaching, we also need to pay attention to the development of innovative sports talents. This requires physical education teacher timely change rigid teaching in physical education teaching mode, and pay attention to the cultivation of students' innovative ability in training students' physical qualities and abilities at the same time.

\section{Summary}

With the speeding up of social changes, development of education and the talents demand quality of modern society, innovation and improvement of teaching mode and methods have not stopped, and physical education teaching is no exception. The purpose of physical education teaching is to cultivate students' sports accomplishment and ability, and set up the consciousness of lifelong physical exercise. For better sports teaching, sports teacher using sports journals as auxiliary tool is a very good choice. That is because sports journals have unique advantages over traditional teaching materials: (1) rich sports periodicals resources with fast update speed; (2) improve traditional teaching mode and stimulate interest in learning. Sports journals auxiliary function of physical education teaching mainly displays in following four aspects: (1) make fast passage between campus and social communication; (2) have free access to information between 
teachers and students and broaden their horizons; (3) broaden teachers' theoretical knowledge and improve teachers' professional level; (4) cultivate students' interest, and improve students' sports skills. Sports journals have an important supporting role in physical education teaching, but in the use of sports journals in physical education teaching, the teacher should pay attention to three points: (1) give full play to students' initiative with reasonable guide; (2) select appropriate sports journals with reasonable arrangement of progress; (3) associate theory with practice, and pay attention to sports innovative talent training. This paper has important theory guiding significance and reference value for physical education teacher using sports journals in auxiliary teaching.

\section{References}

[1] Gui Jiansheng. Journal of education's improvement role in primary and secondary school teachers of professional development [J] Journal of Hebei Normal University (Education Sciences), 2004 (6)

[2] Li Muyang. Feasibility study of track and field sports theory teaching with auxiliary of academic periodicals [J] Sports Journal, 2011, (18)

[3] Fang Chenhua. Rogers "student-centered" teaching theories review [M] Beijing: Science Press, 1990:211-233

[4] Xia Chengqian. On sports teachers' professional development goals from different social groups' understanding of PE teachers social role [J]. Journal of Nanjing Institute of Sport (Social Science Edition), 2002 (04)

[5] Zhang Shaoli, Liu Bingquan, Jiang Zhiqiang, Xu Kaichun. On sports education professional students’ education practice new model [J]. Journal of Shenyang Sports Institute. 2002 (02) 